\title{
Transabdominal Doppler ultrasound evaluation of blood flow patterns of the uterine arteries in cervical cancer patients in Zaria, North-Western Nigeria
}

\author{
I. Garba, ${ }^{1}$ M.Z. Ibrahim, ${ }^{2}$ S. Lawal, ${ }^{2}$ N.D. Chom, ${ }^{2}$ P.O. Ibinaiye ${ }^{2}$ \\ ${ }^{1}$ Department of Radiology, General Hospital, Minna, Niger State; ${ }^{2}$ Departments of Radiology, Ahmadu \\ Bello University/Ahmadu Bello University Teaching Hospital, Zaria, Nigeria
}

\begin{abstract}
Cervical cancer remains an important health issue especially in the developing countries that account for about $85 \%$ of the world burden of cervical cancer. Finding a role for Doppler ultrasound in the evaluation of these patients, may reduce the cost and improve access to management. This study was aimed at evaluating the Doppler flow parameters in patients with cervical cancer when compared to normal subjects. This was a prospective case control, descriptive and observational study conducted in radiology department, ABU Teaching Hospital, Zaria, Nigeria. Eighty-one patients with cervical cancer and 81 age-matched controls had transabdominal Doppler ultrasound examination of the main uterine arteries. The data was analyzed using SPSS version 20.0 Chicago Illinois USA. Difference between two groups was tested using student ttest and $\mathrm{P}<0.05$ considered as statistically significant. The mean Resistivity Index (RI) and Pulsatility Index (PI) were significantly lower in patients with cervical cancer than the control $(\mathrm{P}<0.0001)$. The mean end diastolic velocity was significantly higher in patients than the control $(\mathrm{P}<0.0001)$. There was however no significant difference in the mean peak systolic velocity in patients and
\end{abstract}

Correspondence: Muhammad Zaria Ibrahim, Department of Radiology, Ahmadu Bello University/Ahmadu Bello University Teaching Hospital, Zaria, Nigeria.

Tel.: +2348038065356

E-mail: muibza@gmail.com

Key words: Cervical cancer, blood flow patterns, uterine arteries, transabdominal doppler.

Contributions: the authors contributed equally.

Conflict of interest: the authors declare no potential conflict of interest.

Funding: none.

Received for publication: 28 May 2019.

Revision received: 15 June 2019.

Accepted for publication: 15 June 2019.

This work is licensed under a Creative Commons Attribution NonCommercial 4.0 License (CC BY-NC 4.0).

(C) Copyright: the Author(s), 2019

Licensee PAGEPress, Italy

Annals of African Medical Research 2019; 2:76

doi:10.4081/aamr.2019.76 control $(\mathrm{P}=0.97)$. The findings have demonstrated that significant differences exist in the uterine artery Doppler flow parameters in patients with cervical cancer compared to the healthy controls. This emphasizes the role of Doppler scan in the evaluation and management of patients with cervical cancer.

\section{Introduction}

Cancer of the cervix is a malignant disease of the uterine cervix. The most common histologic types of cervical cancer are squamous cell carcinoma $(69 \%)$ and adenocarcinoma $(25 \%) .{ }^{1}$ Squamous cancer is preceded by a premalignant phase that usually lasts for about 10 years. With regular, frequent screening, most are detected at the premalignant phase and can be treated readily.

In women, cervical cancer is the $4^{\text {th }}$ most common malignancy worldwide. $^{2}$ The frequency varies considerably between developed and developing countries. It is the second most common cancer in developing countries, but only the tenth most common in developed countries. ${ }^{3}$ Worldwide, more than 528,000 women were diagnosed with cervical cancer in 2012, while more than 266,000 women are estimated to have died from cervical cancer in same year, $85 \%$ of which occur in the developing countries. ${ }^{2}$

Human papilloma virus (HPV) infection is central to the development of cervical neoplasia and can be detected in $99.7 \%$ of cervical cancers. ${ }^{4}$ In most western countries, availability of screening tests and vaccine against HPV infections has led to $75 \%$ decrease in the incidence and mortality from cervical cancer over the past 50 years in these countries. ${ }^{5,6}$ In Nigeria, it is the commonest gynecological cancer, ${ }^{7-9}$ with a national incidence of $250 / 100,000$ women. ${ }^{10}$

Angiogenesis has been regarded as an essential event for tumor growth and progression. ${ }^{11}$ The new formed vessels are structurally different from the normal ones. Arteriovenous shunts and the absence of a muscular layer, both typical features of neo-angiogenesis, result in a high flow velocity and low resistance respectively. ${ }^{12}$ Angiogenesis in cervical cancer has been found to be an independent prognostic factor, ${ }^{13,14}$ as well as a predictor of disease recurrence. ${ }^{15,16}$

Traditionally angiogenesis in tumoral tissue is assessed by immune-histochemical staining, but with the application of ultrasound Doppler imaging, tumor vascularity and therefore the process of angiogenesis can be observed in vivo. ${ }^{17}$

Doppler ultrasound may be used in several modes: pulsed Doppler, color Doppler and power Doppler modes. ${ }^{18}$

Uterine artery Doppler ultrasonography may be performed via the transvaginal or transabdominal route. Transvaginal route allows the use of high frequency transducer but may however elicit bleeding in patients with exophytic cervical tumor. For the purpose 
of this study the transabdominal route was utilized.

Imaging techniques are increasingly used in the pre-treatment work-up of cervical cancer. ${ }^{19}$ The use of MRI for local extent of disease evaluation and PET-Scan for distant disease assessment are considered as first-line techniques, ${ }^{20,21}$ in high resource countries where these imaging modalities are readily available and affordable. The use of both gray and Doppler ultrasound in the evaluation of cervical cancer patients is an attractive modality because it is cheap, readily available and can be repeated severally without exposing the patients to any risk of ionizing radiation.

Therefore, this study was aimed at evaluating the blood flow pattern in the uterine artery in patients with cervical cancer when compared to normal subjects using Doppler ultrasound.

\section{Materials and Methods}

This prospective study was carried out in the Department of Radiology, Ahmadu Bello University Teaching Hospital, located in Zaria, Kaduna state, Nigeria. Zaria has a population of about $975,153 .^{22}$ The study was conducted over a period of seven months following an approval from Research and Ethics Committee. The study population was patients with histological diagnosis of cervical cancer attending the Gynecologic oncology and Radio-oncology clinic prior to receiving treatment. The controls were healthy adult women, matched for age recruited from the hospital, university and the host communities.

The inclusion criteria (cervical cancer patients) was newly diagnosed women with histological diagnosis of cervical cancer, with or without vaginal bleeding. While that of the controls was consenting normal adult women within the age range of the cervical cancer patients.

The exclusion criteria (control) include: non-consenting subjects, pregnant women with gynecological or other tumors, dysfunctional uterine bleeding, diabetic patients, peripheral vascular disease, women who have had previous hysterectomy, patients with hemodynamic instability. However, the exclusion criteria (patients) were: other gynecological tumors other than Cervical cancer, prior treatment of the cervical cancer, pregnant women, diabetic patients, peripheral vascular disease, patients with previous hysterectomy, patients with hemodynamic instability

\section{Sample size determination}

Estimation of the sample size for this study was based on the Fishers statistical formula: ${ }^{23}$

$$
\mathrm{N}=\mathrm{Z}^{2} \mathrm{Pq} / \mathrm{d}^{2}
$$

where $\mathrm{N}=$ minimum sample size, $\mathrm{Z}=$ percentage of the standard normal distribution curve which defines $95 \%$ confidence interval and equal to $1.96 . \mathrm{P}=$ prevalence rate from previous study.

Based on the study of Durowade et al. ${ }^{24}$ the prevalence of positive cervical cytology was $5 \%$. So, the minimum sample size was $1.96^{2} \times 0.05 \times 0.95 / 0.05^{2}=73$. In addition, $10 \%$ attrition was considered which translated to about 7 . A total of 81 patients were recruited for the study.

\section{Technique of doppler ultrasound of the uterine artery}

Mindray $(\mathrm{DC}-8) \circledR$ ultrasound machine, China, equipped with with $5 \mathrm{MHz}$ curvilinear probe. Examination couch with clean bed linen and pillow, Ultrasound coupling gel. The procedure was first explained to the participants in clear terms. They were made to understand that the procedure is painless and may be of benefit to them, as any incidental finding would be communicated to the doctor managing them, which may add some value to their management. After obtaining an informed consent, subjects were asked to fill their bladder by drinking one or more liters of water and by not urinating for at least one hour prior to the examination. Those who already had full bladder were exempted from taking the fluid. The subjects laid supine, hands by the side and the head supported with a pillow. A clean piece of drape was spread on the subjects to cover her from the pubic symphysis to the knee and the abdomen exposed to the umbilicus. Coupling gel was applied to the probe and the ultrasound machine settings optimized for the examination. The probe was moved across the lower abdomen and the pelvic organs assessed on 2D-Gray scale for any mass. The cervical mass was then evaluated on a gray scale and a three-dimensional measurement of the mass was obtained in sagittal and transverse view using an electronic caliper (Figure 1). To visualize the uterine artery, amid sagittal section of the uterus was obtained and the cervical canal identified. The probe was then moved laterally until the paracervical vascular plexus was seen, the Color Doppler was then turned on and the uterine artery identified as it is seen crossing the external iliac vessels (Figure 1). Pulsed wave Doppler was then turned on and the Doppler gate placed and adjusted to cover the entire cross-sectional area of the vessel just distal to the point of crossing. The pulsed wave Doppler was then activated and the measurement taken after optimization of the Doppler settings. The same process was repeated on the contralateral side if the vessel was not identified clearly on one side. The parameters- PI, RI, PSV and EDV were automatically calculated by the machine. An average of two regular consecutive cycles of equal heights was used for the calculation (Figure 2).

The Doppler measurement was optimized as follows;

Angle of insonation of less than $60^{\circ}$ was used.

Complete alignment of the Doppler gate with the blood flow was ensured.

The size of the color box was kept as small as possible to include only the studied area.

The Doppler gate was adjusted to ensure the recording of maximum velocities and also ensure that only measurement from the vessel of interest is recorded.

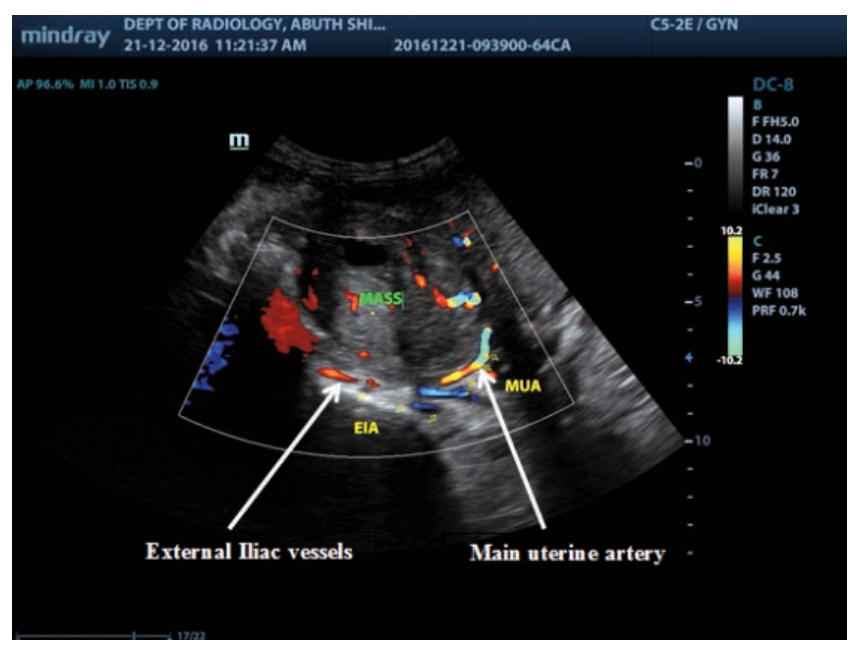

Figure 1. Color Doppler image of the uterine artery and the external iliac vessels in a 56 year old woman with FIGO stage IIIB cervical cancer. 
The velocity scale or pulse repetition frequency (PRF) was appropriately adjusted to prevent aliasing.

\section{Data analysis}

The results and data generated for cervical cancer patients and control group was first entered into the Excel data sheet before being analyzed using statistical package for social sciences (SPSS) version 20.0, 2011 Chicago, Illinois USA. Statistical analysis of the Doppler parameters (PI, RI, PSV, EDV), clinical and demographic variables was performed. Means and standard deviation of the variables was computed and the result presented in appropriate tables, graphs and charts. The difference in PSV, EDV, RI and PI measurements of patients with cervical cancer and control group was tested using student t-test, with $\mathrm{P}<0.05$ considered as statistically significant. ${ }^{25}$

\section{Results}

One hundred and sixty-two women were enrolled in the study comprising 81 cervical cancer patients and 81 normal subjects. The mean age of the patients was $51.80 \pm 6.69$ (range, 33-75) years, while the mean age of the controls was 49.94 \pm 7.01 (range, 31-73) years. No statistical significant difference in the mean age of the two groups $(\mathrm{P}=0.087)$. Sixty-nine $(85.2 \%)$ of the patients had abnormal vaginal bleeding while five $(6.2 \%)$ presented with leakage of urine per vaginum but none had leakage of fecal matter per vaginum.

Most of the patients $(91.3 \%)$ were in their $5^{\text {th }}$ and $6^{\text {th }}$ decades of life (40-59), with the highest frequency $(50.6 \%)$ occurring in the age group 50-59. The lowest incidence was among the age group $>60$ years (Table 1 ). Similarly, most of the controls $(90.1 \%)$ were in their $5^{\text {th }}$ to $6^{\text {th }}$ decade of life, with the age group 40-49 having the highest frequency (Table 2).

Most patients presented between seven months to eighteen months of onset of symptoms (Figure 3).

Based on FIGO staging, most patients $(92.6 \%)$ presented with advance stage disease (IIB-IVA). Stage IIIB was the commonest $(40.7 \%)$ form of presentation (Table 3 ).

Seventy-one of the patients had squamous cell histology while the remaining ten patients had columnar histology (Figure 4).

The mean EDV of the patients was significantly higher than that of the controls. The mean PSV of the patients was also higher than that of the control, but the difference was not statistically significant. The mean RI and the PI of the patients were significantly lower than that of the controls (Table 4).

\section{Discussion}

Out of the total 81 patients with cervical cancer enrolled in the study, $90.8 \%$ were in the age group 40-59 with a mean age of $51.8 \pm 6.69$ years. This is higher than the findings of Sule et al. ${ }^{26}$ who reported the mean age of $47.61 \pm 11.55$ years among cervical cancer patient in Zaria but lower than the findings of Ijaiya et al., ${ }^{27}$ who reported a higher mean age of 54.7years in Ilorin.

Majority $(81.5 \%)$ had advanced disease (IIB-IVB) at presentation, with stage IIIB being the commonest (40.7\%) form of presentation. Sule et al., ${ }^{26}$ in their study reported similar findings where $79.71 \%$ presented with advanced disease. Anorlu et al. ${ }^{28}$ observed that late presentation of patients with cervical cancer in Lagos was largely due to patients' delay in seeking health care and care

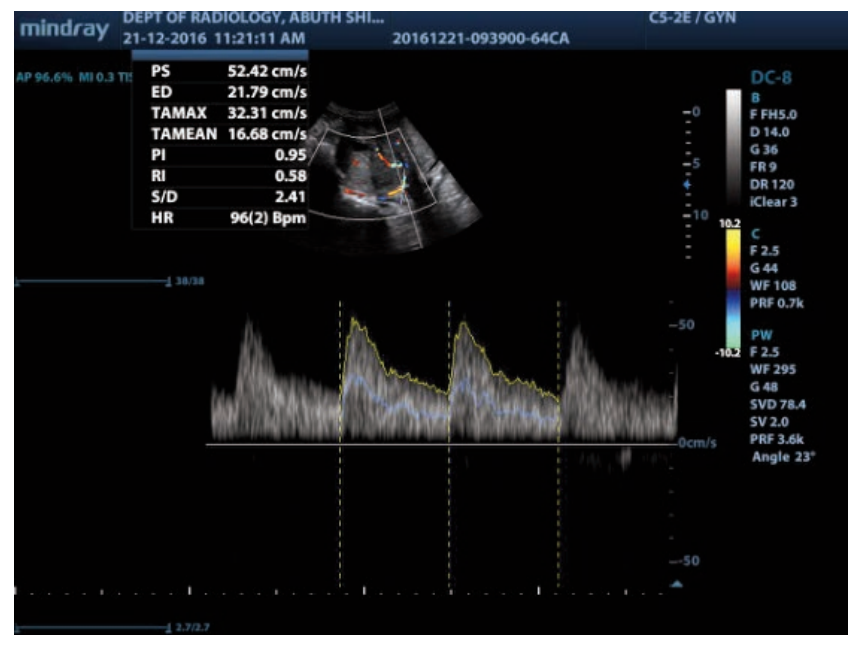

Figure 2. Pulsed Doppler examination of the uterine artery in a 56 year old woman with FIGO stage IIIB cervical cancer, with high $\mathrm{EDV}=21.79 \mathrm{~cm} / \mathrm{s}$, low $\mathrm{RI}=0.58$ and $\mathrm{PI}=0.95$.

Table 1. Age-frequency distribution of the patients with cervical cancer.

\begin{tabular}{lcc}
\hline Age group & Frequency & Percentage \\
$30-39$ & 3 & 3.7 \\
$40-49$ & 33 & 40.7 \\
\hline $50-59$ & 41 & 50.6 \\
$60-69$ & 3 & 3.7 \\
\hline$>69$ & 1 & 1.2 \\
Total & 81 & 100 \\
\hline
\end{tabular}

Table 2. Age-frequency distribution of the control group.

\begin{tabular}{lcc} 
Age group & Frequency & Percentage \\
$30-39$ & 2 & 2.5 \\
$40-49$ & 40 & 49.4 \\
\hline $50-59$ & 33 & 40.7 \\
$60-69$ & 5 & 6.2 \\
\hline 769 & 1 & 1.2 \\
Total & 81 & 100 \\
\hline
\end{tabular}

Table 3. Shows the distribution of the patients by clinical (FIGO) staging.

\begin{tabular}{lcc}
\hline FIGO stage & Frequency & Percentage \\
IA & 0 & 0 \\
IB & 2 & 2.5 \\
\hline IIA & 4 & 4.9 \\
IIB & 19 & 23.5 \\
\hline IIIA & 8 & 9.9 \\
IIIB & 33 & 40.7 \\
IVA & 15 & 18.5 \\
IVB & 0 & 0 \\
Total & 81 & 100
\end{tabular}


providers' delay in referring patients to a tertiary hospital.

Squamous cell carcinoma was the commonest histological type constituting $87.7 \%$. Similar findings were reported by Abdul et al. ${ }^{29}$ in Zaria (89.2\%) and Ijaiya et al., ${ }^{27}$ in Ilorin (85.2\%). Egbang et al. in Cameroon observed that squamous cell carcinoma was the commonest histological type accounting for $81.5 \%{ }^{30}$ PerezGomez et al. ${ }^{31}$ in a 15 year review in Spain observed that squamous carcinoma accounted for $73 \%$ of the histological types, less than what was observed in this study.

It was observed that patients with cervical cancer showed significantly lower mean RI and PI, and significantly higher mean EDV compared to healthy control. The mean PSV of the cervical cancer patients was also higher than that of the control but the difference was not statistically significant.

The above observation signifies a reduction in the uterine artery vascular bed resistance in patients with cervical cancer. Previous studies in the past have observed that the vascularity of malignant tumors is entirely different from that of the normal tissue. ${ }^{11}$ The tumoral blood vessels are abnormal with respect to cellular composition and basement membrane, resulting in increased vascular permeability, fragility, aneurysm formation as well as arteriovenous fistulas, ${ }^{32,33}$ which may result in the reduction of the vascular bed resistance of the uterine artery in cervical cancer. Findings in this study are consistent with the study reported by Breyer et al. ${ }^{34}$ They reported a significantly lower RI and PI in the descending uterine artery among cervical cancer patients compared to the control group. They also similarly observed no significant difference in the PSV between the two groups. The mean RI and mean PI among the patients with cervical cancer in their study were however higher than the values obtained in this study. The transvaginal route of examination and the choice of the descending uterine artery adopted by the authors may have accounted for the relatively lower values observed. Enzelsberger et al., ${ }^{35}$ and Di Vagno et al., ${ }^{36}$ also reported similar findings using the RI and PI. Greco et al., ${ }^{37}$ however reported findings that differ from those observed in this study. They found no significant difference in the PI, RI and MSFV between 23 cervical cancer patients and 20 healthy controls. The small sample size in their study may have affected the outcome of their results.

Belitsos et $a l,{ }^{38}$ using three-dimensional power Doppler indices of Vascular Index (VI), Flow Index (FI) and Vascular Flow Index (VFI) observed that all the indices were significantly higher in the cervical cancer group and the precancerous group than in control group. The power Doppler indices employed by Belitsos and co-authors, being a more sensitive measure of flow and vascularization within an organ and hence its ability to measure more precisely the differences in the cervical vascularity of a cervical cancer patients and healthy controls may support the findings in our study.

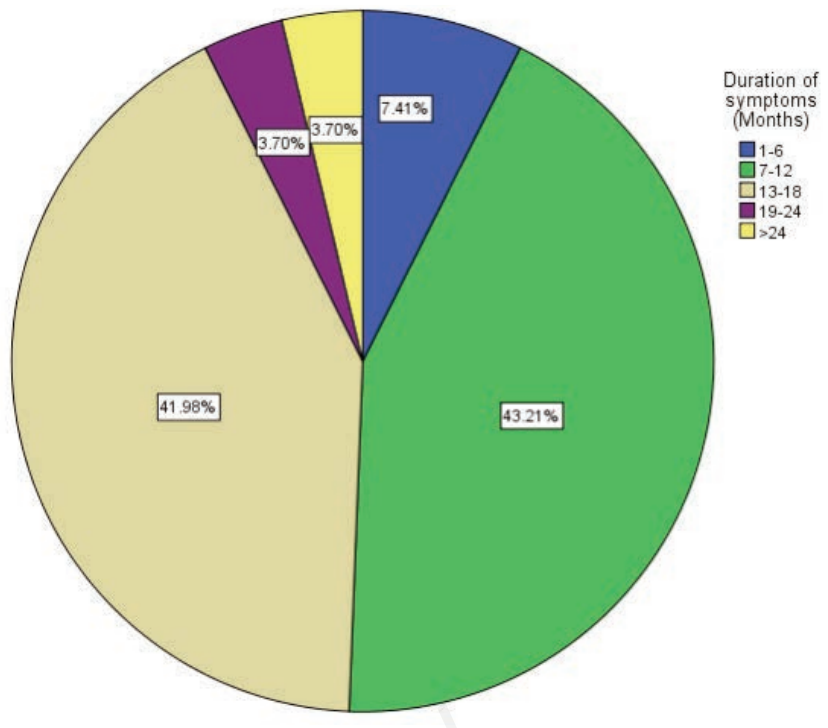

Figure 3. Distribution of the patients with cervical cancer by duration of presenting symptoms.

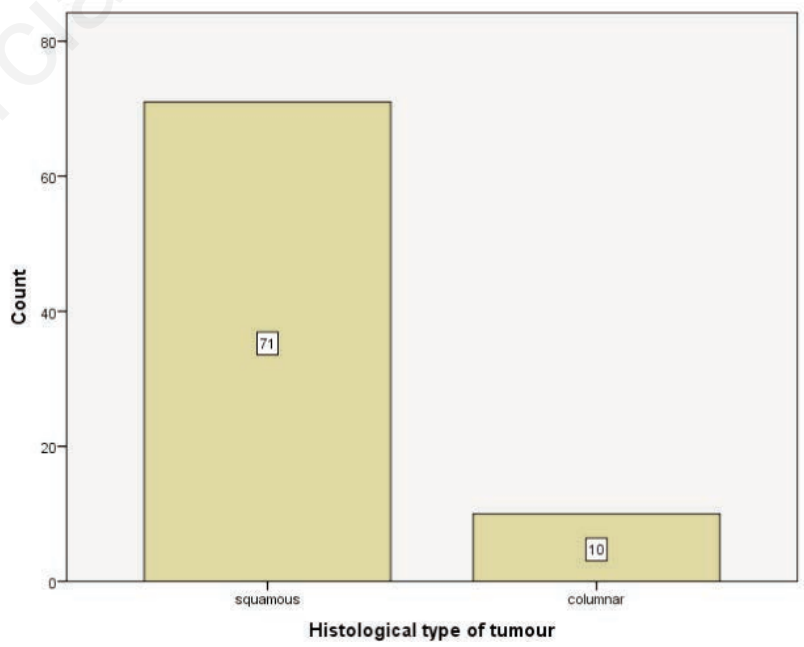

Figure 4. Distribution of the cervical cancer patients by histological type.

Table 4. Shows the Mean \pm standard deviation of the uterine artery Peak Systolic Velocity, End Diastolic Velocity, Resistance Index and Pulsatility Index of the patients and control.

\begin{tabular}{lcccc} 
Doppler measurement & Patient & Mean \pm SD & P-value & Signifficance \\
Peak systolic velocity & $50.69 \pm 6.18$ & $48.96 \pm 6.97$ & 0.97 & Not significant \\
End diastolic velocity & $17.5 \pm 6.08$ & $7.53 \pm 3.01$ & $<0.0001$ & Significant \\
\hline Resistance index & $0.61 \pm 0.11$ & $0.85 \pm 0.07$ & $<0.0001$ & Significant \\
Pulsatility index & $1.18 \pm 0.34$ & $2.30 \pm 0.55$ & $<0.0001$ & Significant \\
\hline N. & 81 & 81 & & \\
\hline
\end{tabular}

SD, Standard deviation. 
Table 5. Showing the mean \pm standard deviation of the uterine artery Peak systolic velocity, End diastolic velocity, Resistance Index and Pulsatility Index of FIGO stage I/II and stage III/IV cervical cancer patients.

\begin{tabular}{lcccc} 
Doppler measurement & Stage I/I & Mean \pm SD & P-value & Significance \\
Peak systolic velocity & $48.00 \pm 6.68$ & $51.89 \pm 5.60$ & 0.008 & Significant \\
End diastolic velocity & $15.85 \pm 5.08$ & $18.25 \pm 6.08$ & 0.076 & Not significant \\
\hline Resistance index & $0.65 \pm 0.08$ & $0.60 \pm 0.12$ & 0.028 & Significant \\
Pulsatility index & $1.27 \pm 0.29$ & $1.14 \pm 0.36$ & 0.12 & Not significant \\
\hline N & 25 & 56 & & \\
\hline
\end{tabular}

In this study (Table 5), when the patients were divided into two groups of stage I/II and stage III/IV disease based on FIGO staging, a significantly lower RI, and higher PSV was observed among patients with stage III/IV disease compared to those with stage I/II disease but no significant difference in the EDV and PI between the two groups. Testa et al. ${ }^{39}$ observed that the PSV was significantly higher among patients with FIGO stage III/IV disease compared to those with stage I/II disease but found no difference in the RI with respect to the FIGO staging and histological type. In this study the finding is not in total agreement with that of Testa and co-authors above. Clinical staging (FIGO staging) has been found to underestimate or overestimates the actual disease extent in significant number of cases,${ }^{40,41}$ this may have accounted for the difference in this study and that of Testa et al. ${ }^{39}$ The index study found no significant difference in the flow parameters with respect to histological types, similar to the findings of Testa et al. ${ }^{39}$

\section{Limitation}

Ultrasonography is operator dependent, more so great deal of technique is required in Doppler ultrasound if useful results are to be generated; as a result, the examination was carried out under the supervision of consultants (co-authors) with tremendous experience in vascular ultrasound imaging.

Bowel gas shadows in patients who find it difficult to maintain a full bladder was one of the limitations; this was overcome in most patients by graded compression which successfully displaced the bowel gas in most instances.

\section{Conclusions}

The findings in this study have demonstrated that a significant difference exists in the uterine artery Doppler parameters evaluated between patients with cervical cancer and healthy women. Although there were some overlaps in the individual values of the parameters assessed between the patients and the control which would affect the sensitivity and specificity of the parameters when used as a diagnostic tool; however, the findings may become useful in the evaluation and management of cervical cancer patients.

\section{References}

1. Ries LAG, Melbert D, Krapcho M, et al. SEER Cancer Statistics Review, 1975-2004. National Cancer Institute. Bethesda, MD. Available from: http://seer.cancer.gov/csr/ 1975 2004/. Accessed on $15^{\text {th }}$ June 2015.

2. WHO. Comprehensive Cervical Cancer Control. Available from http://www.who.int/reproductivehealth/publications/cancers/cervicalcancer-guide/en/. Accessed on October 2015.

3. Jacques F, Hai-Rim S, Freddie B, et al. Estimates of worldwide burden of cancer in 2008. Int J Cancer 2010;127:2893-17.

4. Walboomers JM, Jacobs MV, Manos MM, et al. Human papilloma virus is a necessary cause of invasive cervical cancer worldwide. J Pathol 1999;189:12-9.

5. WHO/ICO Information center of human papilloma virus and cervical cancer: human papilloma virus and related cancers in the world. Summary report 2010. Available from: http://www.who.int/hpvcentre/en. Accessed on $20^{\text {th }}$ June 2015.

6. Willoughby BJ, Faulkner K, Stamp EC, Whitaker CJ. A descriptive study of the decline in cervical screening coverage rates in the North East and Yorkshire and the Humber regions of the UK from 1995-2005. J Public Health (Oxf) 2006;28: 355-60.

7. Kyari O, Nggada H, Mairiga A. Malignant tumours of female genital tract in north eastern Nigeria. East Afr Med J 2004;81:142-5.

8. Uzoigwe SA, Seleye-Fubara D. Cancer of the uterine cervix in Port Harcourt, Rivers State: a clinic-pathological review. Niger J Med 2004;13:110-3.

9. Yakasai IA, Ugwa EA, Otubu J. Gynaecological Malignancies in Aminu Kano Teaching Hospital Kano: A 3 year review. Nig J Clin Pract 2013;16:63-6.

10. Adewole IF, Edozien LC, Babarinsa IA, Akang EE. Invasive and in situ carcinoma of the cervix in young Nigerians. A clinic-pathologic study of 27 cases. Afr J Med Sci 1997;26:191-3.

11. Folkman J, Watson K, Ingler D, Hanahan D. Introduction of angiogenesis during the transition from hyperplasia to neoplasia. Nature 1989;339:58-61.

12. Kidron D, Bernheim J, Aviram R, et al. Resistance to blood flow in ovarian tumours: correlation between resistance index and histological patterns of vascularisation. Ultrasound Obstet Gynecol 1999;13:425-30.

13. Kaku T, Hirakawa T, Kamura T, et al. Angiogenesis in the adenocarcinoma of the uterine cervix. Cancer 1998;83:1384-90.

14. Abulafiya O, Sherer DM. Angiogenesis in the uterine cervix. Int J Gynaecol Cancer 2000:349-57.

15. Obermair A, Wanner C, Bilgi S, et al. Tumour angiogenesis in stage 1B cervical cancer: Correllation of microvessel density with survival. Am J Obstet Gynaecol 1998;178:314-9.

16. Dinh TV, Hannigan EV, Smith ER, et al. Tumour angiogenesis as predictor of recurrence in stage $1 \mathrm{~b}$ squamous cell carcinoma of the cervix. Gynecol Oncol 1996;87:751-4.

17. Taylor KJ, Ramos I, Cater D, et al. Correlation of Doppler ultrasound signals with neovascular morphologic features. Radiology 1998;166:57-62. 
18. Maulik D, Ivica Z. Doppler in obstetrics and gynaecology. $2^{\text {nd }}$ ed. New York: Springer-verlage; 2005. pp 227-242.

19. Follen M, Levenback CF, Lyer RB, et al. Imaging in cervical cancer. Cancer 2003;98:2028-38.

20. Choi HJ, Ju W, Myung SK, Kim Y. Diagnostic performance of computer tomography for detection of metastatic lymphnodes in patients with cervical cancer: meta-analysis. Cancer Sci 2010;101:1471-9.

21. Liyanage SH, Roberts CA, Rockwall AG. MRI and PET scans for primary staging and detection of cervical cancer recurrence. Womens Health (Lond Eng) 2010;6:251-267.

22. National Population Commission. 2006 National Demographic Survey. Available from www.population.gov.ng. Assessed on $4^{\text {th }}$ June 2015

24. Durowade KA, Osagbemi GK, Salaudeen AG, et al. Prevalence and risk factors of cervical cancer among women in an urban community of Kwara State, North central Nigeria. J Prev Med Hyg 2012;53:213-9.

25. Bhide A, Acharya G, Bilardo CM, et al. ISUOG Practice Guidelines; use of Doppler ultrasonography in obstetrics. Ultrasound Obstet Gynecol 2013;41:233-9.

26. Sule ST, Shehu MS. Cervical cancer management in Zaria, Nigeria. Afr J Health Sci 2007;14:149-53.

27. Ijaiya MA, Aboyeji PA, Buhari MO. Cancer of the cervix in Ilorin, Nigeria. WAJM 2004;23:319-22.

28. Anorlu RI, Orakwue CO, Oyeneyin L, Abudu OO. Late presentation of patients with cervical cancer to a tertiary hospital in Lagos: what is responsible. Eur J Gynaecol 2004:729-32.

29. Abdul MA, Shittu SO, Mohammed A, Mayun A. NonSquamous cell carcinoma of the cervix in Zaria, Northern Nigeria: A clinicopathological analysis. Ann Afr Med 2006;5:118-21.

30. Egbang NJP, Tchente NC, Owona MLJ, et al. Epidemiological and Histological Profile of Cervical Cancer in Cameroon: About 2078 Cases. Open J Obstet Gynecol 2016;6:232-9.

31. Perez-Gomez B, Martinez C, Navarro C, et al. The moderate decrease in invasive cervical cancer incidence rates in spain (1980-2004); limited success of opportunistic screening? Ann
Oncol 2010;21:61-8.

32. Blood CH, Zetter BR. Tumour interactions with the vasculature: Angiogenesis and tumour metastasis. Biochem Biophys Acta 1990;1032:89-118.

33. McDonald D, Choyke P. Imaging of angiogenesis:from microscope to clinic. Nature Med 2003:713-25.

34. Breyer B, Despot A, Predanic M, Judis S. Characteristics of blood flow in cancer of the uterine cervix. Ultrasound Obstet Gynaecol 1993;3:268-70.

35. Enzelsberger H, Skodler WD, Vavra N, Reinold E. Ultrasonic Doppler flow studies of the uterine artery in women with cervix cancer. Gynaecol Obstet Invest 1991;32:112-4.

36. Di Vagno G, Cormio G, Vimercati A, et al. Transvaginal colour Doppler sonography for monitoring the response to neoadjuvant chemotherapy in patients with locally advanced cervical cancer. Minerva Ginecol 1996;48:463-7.

37. Greco P, Cormio G, Vimercati A, et al. Transvaginal colour Doppler sonography in predicting the response to chemotherapy in advanced cervical carcinoma. Ultrasound Obstet Gynecol 1997;9:49-52.

38. Belitsos P, Papoutsis D, Rodolakis A, et al. Three-dimensional power Doppler ultrasound for the study of cervical cancer and precancerous lesions. Ultrasound Obstet Gynecol 2012;40:576-81.

39. Testa AC, Ferrandina G, Distefano M, al. Colour Doppler velocimetry and three-dimensional colour power angiography of cervical carcinoma. Ultrasound Obstet Gynecol 2004;24:445-52.

40. Lapolla JP, Schlaerth JB, Gaddis O, et al. The influence of surgical staging on the evaluation and treatment of patients with cervical carcinoma. Gynecol Oncol 1986;24:194-206.

41. Delgado G, Bundy B, Zaino R, et al. Prospective surgicalpathological study of disease-free interval in patients with stage 1B squamous cell carcinoma of the cervix; a gynecologic oncology group study. Gynecol Oncol 1990;38:352-7. 